\title{
Brachial Plexus Palsy Due to Axillary Artery Pseudo aneurysm from Penetrating Trauma to Chest
}

\author{
Varun ${ }^{1}$, Megha Tandon ${ }^{2 *}$, IB Dubey ${ }^{2}$ and Ashwani Gupta ${ }^{3}$ \\ ${ }^{1}$ Postgraduate student, Department of General Surgery, Vardhman Mahavir Medical College and Safdarjung Hospital, India \\ ${ }^{2}$ Assistant Professor, Department of General Surgery, Vardhman Mahavir Medical College and Safdarjung Hospital, India \\ ${ }^{3}$ Department of General Surgery, Vardhman Mahavir Medical College and Safdarjung Hospital, India
}

Submission: November 02, 2017; Published: November 20, 2017

*Corresponding author: Megha Tandon, Assistant Professor, Department of General Surgery, Vardhman Mahavir Medical College and Safdarjung Hospital, New Delhi, India, Email: meghasjh@gmail.com

\begin{abstract}
Axillary artery pseudo aneurysm causing brachial plexus palsy after trauma is a rare entity with only few cases reported in the literature. In most of these cases, this injury has been described secondary to a blunt trauma. We present an unusual case of left arm brachial plexus palsy due to compression effect of pseudo aneurysm that includes the origin of left axillary artery following penetrating injury after fall from height. There were not clavicular or rib fractures, or another type of chest trauma to justify such a vascular injury.
\end{abstract}

\section{Introduction}

Traumatic pseudo aneurysm of the axillary artery along with brachial plexus injury is extremely rare and only a few cases have been reported [1-3]. Traumatic lesions of the axillary artery itself are limited to $2.9 \%$ to 9 $\%$ of major arterial injuries [4].

Pseudoaneurysm of the axillary artery following trauma occasionally occur with concomitant injury to the brachial plexus. The reported incidence range from $27 \%$ to $44 \%$ [5]. Anatomically, the brachial plexus lies in close proximity to the axillary artery at the thoracic outlet. The close anatomical relationship make both the vascular and neural structures vulnerable to direct insult caused by penetrating injuries to the shoulder girdle [6]. However, isolated penetrating injury of the axillary artery alone without concomitant brachial plexus injury does occur. Failure to recognize and surgically correct arterial injury in such instances may result in delayed injury of the brachial plexus by compression from an expanding aneurysm.

Even small false aneurysm can result in injury to the plexus, the compression effect being heightened by the fact that a single fascial envelope surrounds the structures [7]. The compression injury of the brachial plexus is often insidious, resulting in a delay in diagnosis and treatment. Furthermore, injuries to the plexus are associated with poor prognosis, are often irreversible, and result in substantial functional impairment of the upper extremity if not treated within 24 hours of presentation [8]. For this reason, arterial injuries of the shoulder girdle should be approached aggressively and treated without delay (Figure 1).

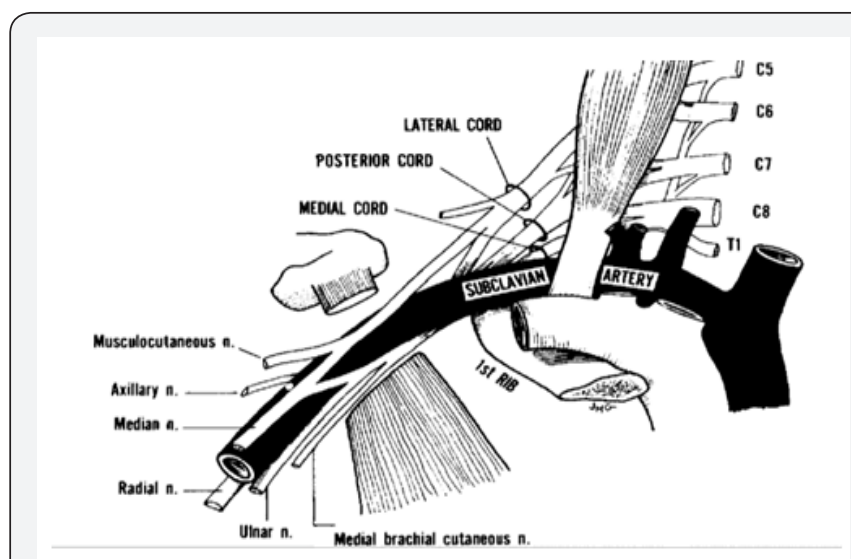

Figure 1: Anatomical relationship of axillary artery with brachial plexus at thoracic outlet.

\section{Case Report}

A 42 year old labourer had suffered a penetrating injury to the left side chest wall below the clavicle following fall from height. He was admitted to a local hospital where he was given first aid and in an attempt to control the bleeding, the laceration over his chest wall was 
sutured and pressure dressing was applied. Subsequently after few days, he developed weakness of the left shoulder and forearm with a localized pulsatile swelling in the left upper chest wall.

He was then referred to our hospital, a tertiary level medical facility upon arrival, he was vitally stable. However, neurological examination of left upper limb revealed diminished sensation in posterior arm, lateral aspect of forearm and in the autonomous zone for the radial nerve. Motor examination revealed weakness in the abductor muscles of the left arm with loss of abduction from 15-90 degrees, loss of arm extension, loss of supination, and loss extension in the wrist, metacarpophalangeal joints.

He underwent an arterial Doppler which revealed a well-defined anechoic lesion on anterior chest wall of size $5.8 \times 4.4 \mathrm{~cm}$, possibly arising from the first branch of the left axillary artery. Computed tomography angiogram was done which revealed a large $8.4 \times 8.5 \times 10.0 \mathrm{~cm}$ sized well defined smoothly marginated lesion in the left axilla in relation to the left axillary artery with central enhancement and absence of peripheral enhancement, and a small communication of $2.5 \mathrm{~mm}$ with the anterolateral part of the left axillary artery, thus confirming the presence of a pseudoaneurysm.
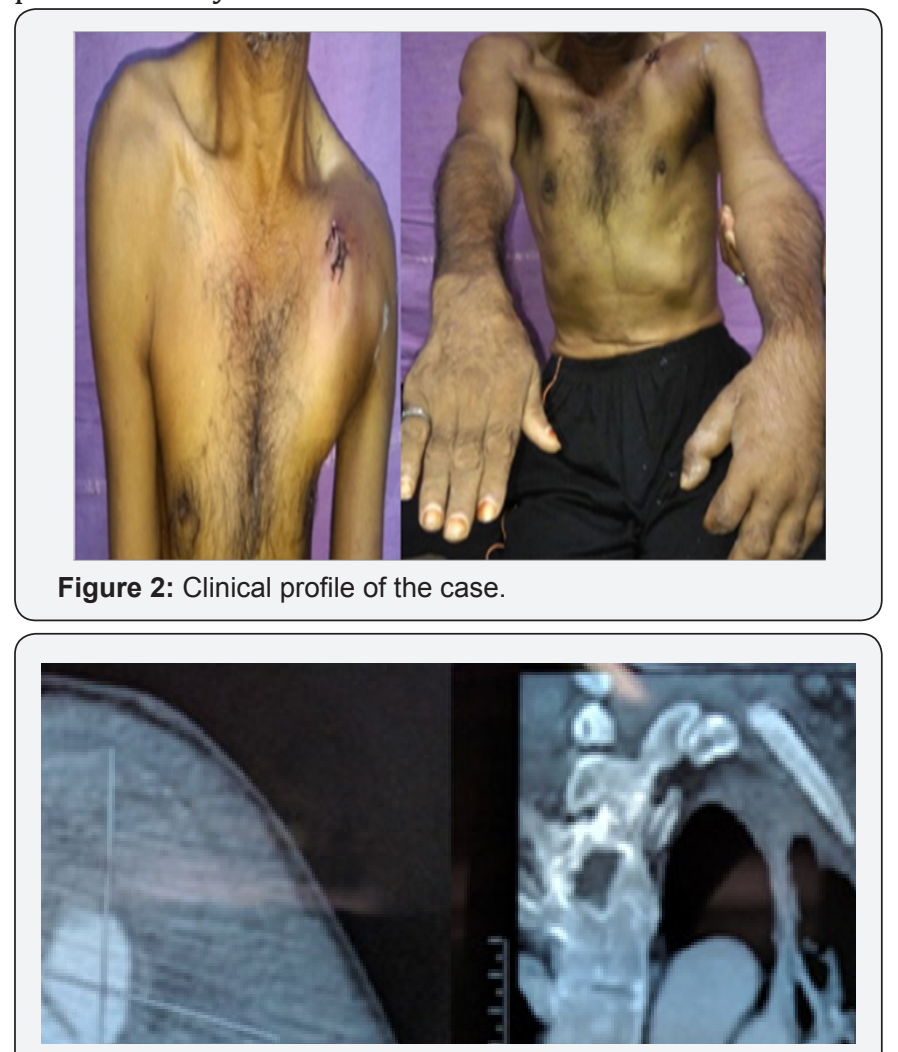

Figure 3: CT Angiogram showing axillary artery aneurysm.

Chest X-ray and CT did not reveal any other injury. No bony fractures were present (Figures $2 \& 3$ ). The patient is being prepared for vascular intervention in form of stenting, however the chances of recovery of brachial plexus is dismal due to delayed presentation. The author wanted to present this case in view of scarce literature and importance of early detection and contemplation of the possible complications based on the site and nature of injury and prompt intervention in order to reduce morbidity.

\section{Discussion}

Pseudoaneurysms result from a variety of mechanisms, including infection, trauma, and surgical procedures. All have in common the disruption of arterial continuity with extravasation of blood into surrounding tissues. This ultimately results in the formation of a fibrous tissue capsule that progressively enlarges because of underlying arterial pressure [9]. In our case, the penetration injury of left axillary artery may have led to pseudoaneurysm formation. Once formed, this traumatic false aneurysm progressively expanded and thrombosed; in doing so, it probably caused neural compression. Because of the close anatomic relationship between the brachial plexus and axillary artery in the thoracic outlet, not only can penetration injury cause direct damage to the neural structure $[10,11]$, but a small false aneurysm will result in compression injury to the plexus [12-15].

The direct damage usually presents no difficulty in diagnosis because of the marked primary neurological deficit. On the contrary, when the plexus is compressed by an expanding false aneurysm, the neurological symptoms and signs often develop insidiously days to weeks later. The period between traumatic event and discovery of pseudoaneurysm has varied in length among four different series [12-15]. Our case had a fairly abrupt onset of prevailing symptoms of brachial plexopathy, five days after trauma.

The diagnosis of brachial plexus palsy attributable to axillary pseudoaneurysm compression may be made by physical examination [12-15]. Electromyography with nerve conduction velocity is complementary and aids in localization of brachial plexus involvement. Duplex ultrasound, computed tomography, magnetic resonance image, and arteriography also can help to determine the nature of the cause. Because brachial plexus palsy has a poor prognosis when recognition is delayed $[12,13,15]$, an aggressive investigation of all traumatic injuries of chest and neck is advocated. Any neck swelling, new bruit or symptoms of brachial plexopathy should arouse clinical suspicion of a pseudoaneurysm. A false aneurysm, even if it is small and asymptomatic, should be treated surgically without delay to prevent permanent neural damage and other associated squeal. 


\section{References}

1. Gallen J, Wiss DA, Cantelmo N, Menzoin JO (1984) Traumatic pseudoaneurysm of the axillary artery: report of three cases and literature review. J Trauma 24(4): 350-354.

2. Helm AT, Watson JS (2002) Compression of the brachial plexus in a patient with false aneurysm of the axillary artery as a result of anterior shoulder dislocation. Journal of Shoulder and Elbow Surgery 11(3): 278-279.

3. Stenning M, Drew S, Birch R (2005) Low-energy arterial injury at the shoulder with progressive or delayed nerve palsy. J Bone Joint Surg $\mathrm{Br}$ 87(8): 1102-1106.

4. Graham JM, Mattox KL, Feliciano DV, DeBakey ME (1982) vascular injuries of the axilla. Ann Surg 195(2): 232-238.

5. Adovasio R, Visintin E, Sgarbi G (1996) Arterial injury of the axilla: an unusual case after blunt trauma of the shoulder. J Trauma 41(4): 754 756

6. Hardy JD, Raju S, Neely WA, Berry DW (1975) Aortic and other arterial injuries. Ann Surg 181(5): 640-653.

7. Braun RM, Newman J, Thacher B (1978) Injury to the brachial plexus as a result of diagnostic arteriography. The Journal of Hand Surgery 3(1): 90-94

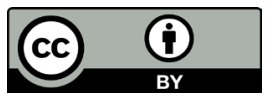

This work is licensed under Creative Commons Attribution 4.0 Licens DOI: 10.19080/OAJS.2017.07.555704
8. Nulsen FE, Kline DG (1973) Acute injuries of peripheral nerves. In: Youmans JR (Ed.), Neurological Surgery. WB Saunders Co, Philadelphia, 2: 1089-1140.

9. Clark ET, Gewertz BL (1995) Pseudoaneurysms. In: Rutherford RB (Ed.), Vascular Surger, ( ${ }^{\text {th }}$ edn), WB Saunders, Philadelphia, pp. 11531161.

10. Braun RM, Newman J, Thacher B (1978) Injury to the brachial plexus as a result of diagnostic arteriography. J Hand Surg 3: 90-94.

11. Paschall RM, Mandel S (1983) Brachial plexus injury from percutaneous cannulation of the internal jugular vein. Ann Emerg Med 12(1): 58-60.

12. Raju S, Carner DV (1981) Brachial plexus compression: Complication of delayed recognition of arterial injuries of the shoulder girdle. Arch Surg 116: 175-178.

13. O'Leary MR (1990) Subclavian artery false aneurysm associated with brachial plexus palsy: A complication of parenteral drug addiction. Am J Emerg Med 8: 129-133.

14. Donohoe CD, McGuire TJ (1991) Delayed weakness following a gunshot wound. Postgrad Med 90(8): 219-220.

15. Hansky B, Murray E, Minami K, Körfer R (1993) Delayed brachial plexus paralysis due to subclavian pseudoaneurysm after clavicular fracture. Eur J Cardiothorac Surg 7: 497-498.

\section{Your next submission with Juniper Publishers will reach you the below assets}

- Quality Editorial service

- Swift Peer Review

- Reprints availability

- E-prints Service

- Manuscript Podcast for convenient understanding

- Global attainment for your research

- Manuscript accessibility in different formats

( Pdf, E-pub, Full Text, Audio)

- Unceasing customer service

Track the below URL for one-step submission https://juniperpublishers.com/online-submission.php 